\title{
Detection of quantitative trait loci for reproduction and production traits in Large White and French Landrace pig populations (Open Access publication)
}

\author{
Thierry TRIBOUT ${ }^{1 *}$, Nathalie IANNUCCELLI ${ }^{2}$, Tom DRUET ${ }^{1}$, Hélène \\ GILBERT $^{1}$, Juliette RIQUET ${ }^{2}$, Ronan GUEBLEZ ${ }^{3}$, Marie-José \\ MERCAT $^{3}$, Jean-Pierre BIDANEL ${ }^{1}$, Denis MILAN ${ }^{2}$, Pascale LE RoY ${ }^{4}$ \\ ${ }^{1}$ INRA UR337 Station de génétique quantitative et appliquée, 78352 Jouy-en-Josas, France \\ ${ }^{2}$ INRA UR444 Laboratoire de génétique cellulaire, 31326 Castanet-Tolosan, France \\ ${ }^{3}$ IFIP Institut du Porc, La Motte au Vicomte, BP 35104, 35651 Le Rheu Cedex, France \\ ${ }^{4}$ INRA UMR598 Génétique animale, 35042 Rennes, France
}

(Received 17 January 2007; accepted 31 July 2007)

\begin{abstract}
A genome-wide scan was performed in Large White and French Landrace pig populations in order to identify QTL affecting reproduction and production traits. The experiment was based on a granddaughter design, including five Large White and three French Landrace half-sib families identified in the French porcine national database. A total of 239 animals (166 sons and 73 daughters of the eight male founders) distributed in eight families were genotyped for 144 microsatellite markers. The design included 51262 animals recorded for production traits, and 53205 litter size records were considered. Three production and three reproduction traits were analysed: average backfat thickness (US_M) and live weight (LWGT) at the end of the on-farm test, age of candidates adjusted at $100 \mathrm{~kg}$ live weight, total number of piglets born per litter, and numbers of stillborn (STILLp) and born alive (LIVp) piglets per litter. Ten QTL with medium to large effects were detected at a chromosome-wide significance level of 5\% affecting traits US_M (on SSC2, SSC3 and SSC17), LWGT (on SSC4), STILLp (on SSC6, SSC11 and SSC14) and LIVp (on SSC7, SSC16 and SSC18). The number of heterozygous male founders varied from 1 to 3 depending on the QTL.
\end{abstract}

quantitative trait locus / pig / commercial population / production trait / reproduction trait

\section{INTRODUCTION}

Three strategies have been applied in livestock for quantitative trait loci (QTL) mapping. The first one, and by far the most widely used in pigs, is based

*Corresponding author: thierry.tribout@jouy.inra.fr 
on the use of experimental intercrosses between distant breeds, for example Large White and Meishan [5], wild boar and Large White [1], or Berkshire and Yorkshire [25]. This approach is powerful, since all F1 animals are expected to be heterozygous for many markers and many QTL. This approach has resulted in mapping hundreds of loci in the pig over the last decade (see PigQTLdb [17]). Nevertheless, the QTL detected using this strategy are essentially those explaining differences in performance between breeds, and are not necessarily the QTL segregating within commercial populations. Consequently, the practical use of these results in pig breeding programs has been limited so far.

A second strategy consists in creating family structures especially for research purposes within commercial populations. Its main advantage is that any mapped QTL should be more directly usable for marker assisted selection than those resulting from experimental intercrosses. Yet, the probability of a commercial population family founder being heterozygous for a QTL is expected to be low, particularly for traits under selection. Thus a large number of families is required to ensure a good power to detect them. This second approach has been less popular in pigs than the use of crossbred designs. However, some experiments have been successfully implemented in commercial pig populations for QTL mapping [37,39].

A third strategy for mapping QTL consists of exploiting existing family structures in commercial populations where field data are routinely recorded and large paternal half-sib families are produced when artificial insemination (AI) is widespread. In this case, provided that DNA is available for the animals of interest, implementation of a long and expensive experimental design is not required. This approach has been widely and successfully used in dairy cattle where AI results in bulls frequently having tens of sons each with tens of daughters with phenotype records (e.g. [6]), but has seldom been used in the pig (e.g. $[13,26])$ where the diffusion of AI boars is lower and consequently the sire families are smaller.

Yet, several favourable elements have made it possible to implement a QTL detection program within the two main French pig populations, i.e. Large White (LW) and Landrace (LR):

- widespread use in the nineties of hyperprolific boars by AI in maternal breeds, resulting in the constitution of large paternal half-sib families;

- storage of phenotype and pedigree records in a national porcine database used for genetic evaluation [35];

- creation of a porcine DNA bank, providing DNA samples for a large number of reproducers from the targeted families. 
Together these events have generated a set of data that resemble a granddaughter design. The eight largest paternal half-sib families available in the two populations were selected for a genome-wide scan for QTL for production and reproduction traits. This paper presents the design and methods used for this detection, and reports the first results of this study.

\section{MATERIAL AND METHODS}

\subsection{Animals and measurements}

The experiment was based on a granddaughter design [41], involving in each family a male founder (generation 1), his sons and daughters (generation 2, referred to as "parents" below), and their sons and daughters (generation 3).

The national database was used to identify large LR and LW purebred halfsib families. For each family, DNA samples from the male founder and parents were taken from the national porcine DNA bank. When no DNA was available, blood samples of animals that were still alive were collected on farm for DNA extraction. The design finally included 239 parents (166 males and 73 females) distributed in 8 half-sib families ( 5 in the LW female line and 3 in the LR breed). Family size averaged 30 genotyped animals per male founder (ranging from 15 to 62) for production traits, but was smaller for reproduction traits (24 genotyped parents on average, ranging from 7 to 56). Within half-sib families, parents had an average of 215 offspring with records for production traits and 70 daughters with records on 3.9 litters for reproduction traits, with large differences between families (Tab. I).

The power of the design as a function of the QTL substitution effect was approximated using the approach described by van der Beek et al. [36], assuming a biallelic QTL with a heterozygosity of $50 \%$ located at $6.7 \mathrm{cM}$ from two flanking markers (average distance between two consecutive markers in the present design). The results are given in Figure 1 for two traits with heritabilities of 0.4 and 0.1 , which correspond to average values for the production and reproduction traits considered in the present study. For simplicity, we assumed a design with eight sire families of equal size, with the same numbers of genotyped parents and of recorded offspring as indicated above for either production or reproduction traits. The power of the design appeared lower for production traits than for reproduction traits (respectively, 0.31 and 0.70 for example for a QTL with a 0.25 phenotypic standard deviation effect, i.e. that explains $3 \%$ of the phenotypic variance), despite the family size for the latter traits being smaller. Actually, the part of genetic variance explained by a QTL 
Table I. Characteristics of the eight families analysed for production and reproduction traits.

\begin{tabular}{|c|c|c|c|c|c|c|c|c|c|c|}
\hline \multirow{2}{*}{\multicolumn{5}{|c|}{$\begin{array}{cc}\begin{array}{c}\text { Family Number of genotyped parents for } \\
\text { production } \\
\text { traits }\end{array} & \begin{array}{c}\text { reproduction } \\
\text { traits }\end{array} \\
\text { sires } & \text { sams }\end{array}$}} & \multicolumn{3}{|c|}{$\begin{array}{l}\text { Number of offspring with } \\
\text { records for production traits } \\
\text { per genotyped parent }\end{array}$} & \multicolumn{3}{|c|}{$\begin{array}{l}\text { Number of daughters } \\
\text { with litter size records }{ }^{\mathrm{b}} \\
\text { per genotyped parent }\end{array}$} \\
\hline & & & & & mean & $\operatorname{mini}^{\mathrm{a}}$ & $\operatorname{maxi}$ & mean & $\operatorname{mini}$ & maxi \\
\hline LW1 & 26 & 3 & 17 & 3 & 135 & 0 & 691 & 39 & 7 & 136 \\
\hline LW2 & 23 & 2 & 18 & 2 & 297 & 0 & 2310 & 97 & 6 & 718 \\
\hline LW3 & 19 & 3 & 15 & 3 & 307 & 0 & 1470 & 94 & 3 & 385 \\
\hline LW4 & 34 & 8 & 30 & 8 & 388 & 0 & 2401 & 121 & 1 & 736 \\
\hline LW5 & 3 & 12 & 3 & 12 & 191 & 29 & 1828 & 51 & 4 & 453 \\
\hline LR1 & 14 & 12 & 9 & 12 & 119 & 0 & 1278 & 46 & 2 & 377 \\
\hline LR2 & 16 & 2 & 5 & 2 & 107 & 0 & 1130 & 86 & 11 & 383 \\
\hline LR3 & 31 & 31 & 25 & 31 & 145 & 0 & 1122 & 43 & 1 & 318 \\
\hline Total & 166 & 73 & 122 & 73 & $\begin{array}{r}\text { Total nu } \\
\mathrm{w}\end{array}$ & & $\begin{array}{l}\text { offspring } \\
\text { rd: }\end{array}$ & $\begin{array}{l}\text { Numb } \\
\text { records }\end{array}$ & & $\begin{array}{l}\text { tter } \\
\text { ered: }\end{array}$ \\
\hline
\end{tabular}

LWi $=\mathrm{i}^{\text {th }}$ Large White family; $\mathrm{LRi}=\mathrm{i}^{\text {th }}$ Landrace family; ${ }^{\text {a }}$ sires and dams without recorded offspring had one own record for production traits; ${ }^{b}$ each daughter had on average 3.9 litter size records.

of a given effect expressed in phenotypic standard deviation unit is higher for a low heritability trait than for a high heritability trait. Consequently, the grandoffspring phenotypes of a 3 generation design become less informative when heritability increases, and the power decreases, as explained in [36].

The phenotypic traits analysed were those routinely collected for selection purposes, i.e.:

- numbers of piglets born in total, born alive and stillborn per litter (TOTp, LIVp and STILLp, respectively) recorded on purebred sows in selection and multiplication herds;

- live weight (LWGT) and average backfat thickness (US_M = mean of six ultrasonic measurements on each side of the spine, $4 \mathrm{~cm}$ from the middorsal line at the shoulder, last rib and hip joint) recorded at the end of the on-farm test (at 148 days of age and $95 \mathrm{~kg}$ on average) on male and female candidates in selection herds;

- age of animals at the end of the test adjusted to $100 \mathrm{~kg}$ (AGE100), using the method and adjustment factors described by Jourdain et al. [19].

\subsection{Markers and genotyping}

A total of 558 microsatellites mapped on the USDA map [30] or on the PIGMaP map [2] were analyzed on 7 of the 8 male founders. They presented 


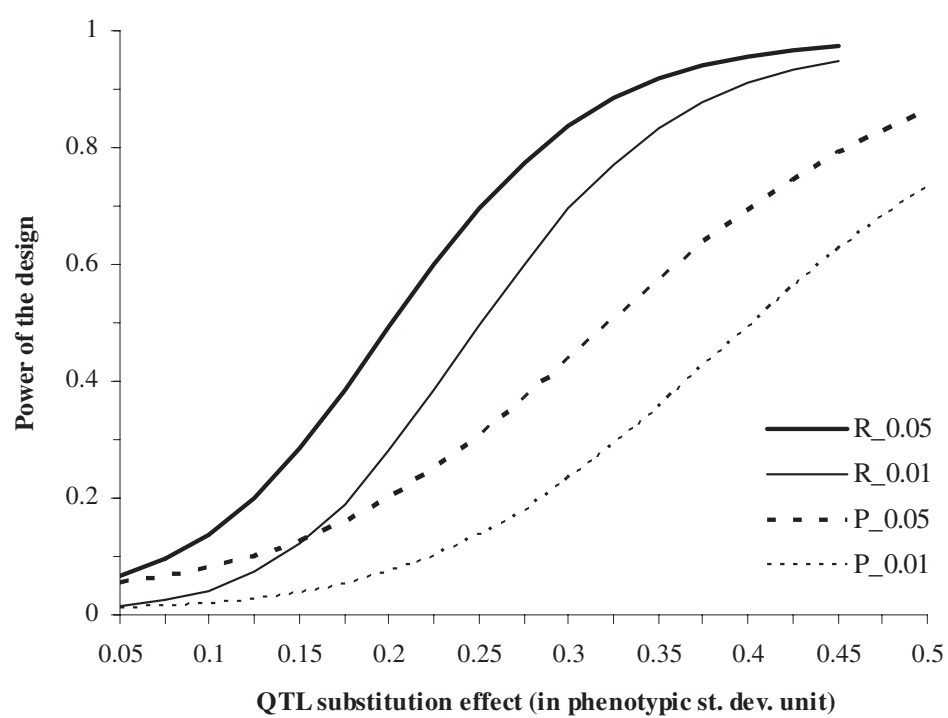

Figure 1. Approximate power of the design for the detection of QTL for production traits and reproduction traits, as a function of the QTL substitution effect. R_0.05 and R_0.01 are, respectively, the power for a 0.1 heritability reproduction trait considering a $5 \%$ or a $1 \%$ type I error. P_0.05 and P_0.01 are, respectively, the power for a 0.4 heritability production trait considering a $5 \%$ or a $1 \%$ type I error.

an average heterozygosity of 52\%. A subset of 144 markers covering the 18 pairs of autosomes was selected on the basis of their informativity and their location on the genome. The list of markers used and the characteristics of genome coverage are given in Appendix I (published in electronic-only form). All the microsatellites are located on the USDA map, the additional PIGMaP marker positions being determined using common markers as a reference. The average distance between two microsatellites was $13.3 \mathrm{cM}(\mathrm{SD}=9.7 \mathrm{cM})$, and average marker informativity was 0.77 .

All founders and parents were genotyped for the 144 markers on automated sequencers at the CRGS platform (Centre de Ressources - Génotypage et Séquençage) of Génopole, Toulouse, Midi-Pyrénées. The fragment length of the PCR products was determined using the Genescan software (ABI; Perkin Elmer) and the genotype of the animals was then obtained using the Genotyper software (ABI; Perkin Elmer). Genotype data were finally checked, validated and stored in the Gemma database [18]. 


\subsection{Statistical analysis}

QTL detection was carried out with the QTLMAP software [12] using the two-step procedure described by Knott et al. [22]: (a) for each chromosome, the probability of each possible phase of the male founders was estimated from their progeny marker information, the most likely phase was retained, and the probabilities of transmission to the offspring were estimated at every position, given this phase; (b) a within-male founder linear regression model was used to test the presence of a QTL every centimorgan along the 18 autosomes with an across family likelihood ratio test. The model was as follows:

$$
G M_{i j}=s_{i}+\left(2 p_{i j}-1\right) a_{i}+e_{i j}
$$

where:

- $s_{i}$ is the effect of the male founder $i$;

- $a_{i}$ is half the substitution effect of the putative QTL carried by the male founder $i$;

- $p_{i j}$ is for parent $j$ from male founder $i$, the probability of receiving one arbitrarily defined QTL allele from $i$ given marker information;

- $e_{i j}$ is the residual, assumed to follow a normal distribution $N\left(0, \sigma_{e i}^{2} / C D_{i j}\right)$, where $\sigma_{e i}^{2}$ is a within-sire family residual variance and $C D_{i j}$ is the reliability of the proof of parent $j$ from male founder $i$ based on its own and progeny information (see App. II for its computation);

- the dependent variable $G M_{i j}$ ("Genetic Merit" of the $j^{\text {th }}$ parent from male founder $i$ ) is a combination of the own performances of the $j^{\text {th }}$ parent from male founder $i$ and of its sons' and daughters' phenotypes corrected for the estimated breeding value of their second parent; this unregressed summary of own and progeny performances is a generalization of the "daughter yield deviation" [38] frequently used for QTL analysis based on granddaughter designs. The formulas used to compute $G M_{i j}$ for production and reproduction traits are given in Appendix II.

The variance component estimates required for the computation of $G M_{i j}$ values were estimated separately for LW and LR populations, using the VCE (version 4.5) software [27]. The data included the pigs of the experiment and their herd $\times$ year contemporaries. Pedigrees were traced back for five generations. The single trait mixed animal models used for litter traits included the fixed effects of sow parity, month of farrowing, and herd*year*type of mating (i.e. AI or natural mating) combination, the age of the sow within parity as a covariate, and the random effects of the boar mate, the permanent environmental effect of the sow, and individual additive genetic value. For production 
traits, the model included the fixed effect of fattening group, age (for LWGT) or live weight (for US_M) of the animal at the end of the on farm test as covariates, as well as the random effects of birth litter and individual additive genetic value.

Then, BLUP analyses were performed using the same models and estimated variance components on data sets including all the performances recorded in LW and LR populations from 1992 to 2003 for production traits and from 1992 to 2005 for reproduction traits, considering five generations of ancestors. The BLUE and BLUP values obtained were used to adjust the data for all the effects of the above models except the additive genetic value (for all traits) and the permanent environmental effect of the sow (for reproduction traits), as well as for the additive genetic values of the parent's mates.

For each trait and each chromosome, 30000 within-family permutations were performed to estimate empirical chromosome-wide significance levels of the test statistics [9]. For each QTL reaching a chromosome-wide significance level of 5\%, the male founders whose family likelihood ratio test exceeded the value of a $\chi^{2}$ distribution with one degree of freedom (i.e. 3.84 for a type I error of 5\%) were considered as heterozygous for the QTL. Then, the average substitution effect of the QTL was calculated as the mean of the substitution effects estimated for the heterozygous male founders.

The $95 \%$ confidence intervals of the QTL locations were estimated by lod drop-off, the bounds of the interval being the two locations whose likelihood was equal to the maximum likelihood minus $3.84\left(=\chi_{(1,0.05)}^{2}\right)$.

\section{RESULTS}

Ten QTL were detected with a 5\% chromosome-wide significance level. Their most likely position, 5\% confidence interval, significance level, average substitution effect and the families they were segregating into are given in Table II.

Estimates of the QTL effects were large, varying from 0.3 to 1.3 phenotypic standard deviations. Nine of the ten detected QTL seemed to be segregating in both LW and LR populations, with a number of heterozygous male founders varying from 1 to 3 depending on the region considered.

Three QTL were identified for fatness, on SSC2 $(P=0.037), \operatorname{SSC} 3(P=$ $0.009)$ and $\operatorname{SSC} 17(P=0.014)$. A QTL was detected for LWGT $(P=0.050)$, and one was suggested for $\operatorname{AGE100~}(P=0.068-$ not shown in Tab. II $)$ at the same position on SSC4. 
Table II. QTL detected with a 5\% chromosome-wide significance level ( $P$-value).

\begin{tabular}{|c|c|c|c|c|c|c|c|c|}
\hline \multirow[t]{2}{*}{ Trait $^{\mathrm{a}}$} & \multirow[t]{2}{*}{$\sigma_{p h}^{\mathrm{b}} \mathrm{h}^{2 \mathrm{c}}$} & \multirow[t]{2}{*}{ SSC } & \multirow{2}{*}{$\begin{array}{l}\text { Location of } \\
\text { maximum }(\mathrm{cM}) \\
{[95 \% \text { C.I. }]^{\mathrm{d}}}\end{array}$} & \multirow{2}{*}{$\begin{array}{c}\text { Marker at maximum } \\
\text { location or } \\
\text { flanking markers }\end{array}$} & \multirow[t]{2}{*}{$P$-value } & \multicolumn{2}{|c|}{$\begin{array}{l}\text { Heterozygous } \\
\text { founders }\end{array}$} & \multirow{2}{*}{$\begin{array}{c}\text { Average } \\
\text { substitution } \\
\text { effect }^{\mathrm{f}}\end{array}$} \\
\hline & & & & & & LW & LR & \\
\hline \multirow[t]{3}{*}{ US_M } & 1.50 .47 & 2 & $15[3-29]$ & MCS364; SW2445 & 0.037 & 1 & 3 & 1.0 \\
\hline & & 3 & 105 [97-129] & SW2408; SW1327 & 0.009 & 2 & 2 & 1.2 \\
\hline & & 17 & $28[15-55]$ & SWR1004; SW1920 & 0.014 & $2 ; 3$ & 1 & 2.0 \\
\hline LWGT & 8.70 .29 & 4 & $62[38-73]$ & SW1073 & 0.050 & 5 & 2 & 7.4 \\
\hline \multirow[t]{3}{*}{ STILLp } & 1.40 .09 & 6 & 88 [79-94] & S0444 & 0.018 & 1 & $2 ; 3$ & 0.6 \\
\hline & & 11 & $66[49-84]$ & SW1415; SW903 & 0.035 & 1 & 2 & 1.0 \\
\hline & & 14 & $28[21-37]$ & SW1125; SW245 & 0.045 & 3 & $1 ; 3$ & 0.4 \\
\hline \multirow[t]{3}{*}{ LIVp } & 3.10 .10 & 7 & 20 [13-29] & S0383; S0064 & 0.018 & 3 & 2 & 1.5 \\
\hline & & 16 & $9[2-32]$ & S0111; SW2411 & 0.050 & 4 & & 2.5 \\
\hline & & 18 & $1[1-8]$ & SW1808 & 0.013 & 5 & 1 & 1.2 \\
\hline
\end{tabular}

a Average backfat thickness (US_M, in kg) and live weight (LWGT, in mm) at the end of the onfarm test; numbers of stillborn (STILLp) and born alive (LIVp) piglets per litter; ${ }^{\mathrm{b}}$ phenotypic standard deviation and ${ }^{\mathrm{c}}$ heritability of the trait (average parameters of the two breeds, estimated by REML on the data); ${ }^{\mathrm{d}}$ lod drop-off $95 \%$ confidence interval of the QTL location; ${ }^{\mathrm{e}} \mathrm{i}^{\text {th }}$ family within each breed: $\mathrm{LW}=$ Large White; $\mathrm{LR}=$ Landrace; ${ }^{\mathrm{f}}$ in trait unit.

Six QTL were mapped for reproduction traits, on SSC6 $(P=0.018)$, SSC11 $(P=0.035)$ and SSC14 $(P=0.045)$ for STILLp, and on SSC7 $(P=0.018)$, $\operatorname{SSC} 16(P=0.050)$ and $\operatorname{SSC} 18(P=0.013)$ for LIVp. While the regions affecting STILLp and LIVp differed, neither of these regions was found to affect TOTp, despite the genetic correlation between these traits.

\section{DISCUSSION}

\subsection{Design and methods}

Exploiting existing familial structures in commercial populations is an approach of choice for QTL mapping, in particular for reproduction traits, since: (1) it avoids the implementation of a long and expensive experimental design; (2) the detected QTL are immediate candidates for marker assisted selection. Conversely, it is by definition limited to the traits routinely recorded by breeders. Mapping QTL for phenotypes that are difficult or expensive to measure on a large number of animals (e.g. behaviour, meat quality or maternal ability traits) is consequently excluded, whereas these are precisely the traits whose 
selection is likely to show the largest gains from the use of markers. For such traits, the development of experimental designs appears almost unavoidable.

In most cases, the dependent variable used in granddaughter designs is either a "daughter yield deviation" (DYD) (e.g. [6, 15]) or an estimated breeding value (BLUP EBV or selection index, e.g. [11,33]) of second generation animals. Estimated breeding values are regressed scores that reflect the amount of data used for their computation, whereas the DYD of a parent is an unregressed weighted average of its daughters' and sons' records adjusted for environmental effects and for the additive genetic values of the parent's mates [38]. When the second generation animals in a granddaughter design have large numbers of progeny with records, the use of EBV or DYD is equivalent $[14,34]$ since the regression of EBV is then limited. Nevertheless, in the present design, some of the second generation animals only had a small number of offspring (e.g. $25 \%$ of the parent animals had less than 20 offspring for production traits), and the use of EBV would lead to underestimated QTL effects. Hence, the use of the DYD approach was preferred. Moreover, the usual DYD approach was extended to include the own performances of the parents in the prediction of their $G M$. This allowed the second generation animals having no recorded progeny to be included in the study and the accuracy of the predicted $G M$ values for the parents with a limited number of offspring to be improved.

Although large substitution effects were estimated for some of the QTL detected here, only a few sires were actually heterozygous for these loci on the basis of the $\chi^{2}$ tests. As a consequence, none of the 10 QTL detected reached the genome-wide significance level $(P \approx 0.003)$. This low power of detection of our design was caused by the limited number of families available (reducing the chances of having heterozygous founders and consequently informative families for QTL) and by the relatively small size of these families. Very large half-sib structures are indeed scarce in LW and LR populations, since breeders limit the number of mated females per boar to maintain genetic variability. Moreover, the storage of boar DNA samples was not systematic before 2002, which resulted sometimes in substantial decrease in the size of the founder families. These losses were partially compensated by considering in the design the available female parents having their own performance and/or recorded progeny.

Despite these limitations, the number of QTL detected exceeds the number of positive results that can be expected by chance. Indeed, one expects only four false positive results at a $5 \%$ elementary significance level for analysis of 18 chromosomes and 6 traits corresponding to four independent traits. 
Our result consequently strongly suggests that several of the QTL reported here correspond to true QTL effects.

\subsection{Results}

Our results show that a part of the phenotypic variance for growth, fatness, number of piglets born alive and number of stillborn piglets per litter observed in LW and LR populations can be explained by the segregation of QTL alleles with large effects. Considering that these traits, with the notable exception of stillbirth, have been intensively and efficiently selected over the last decades in both populations, the chances for the QTL with large effects to be fixed or close to fixation were high. The persistence of segregation of the QTL detected here may be due to additional unfavourable effects (on other traits) counterbalancing their positive effects on the traits considered in this study. A fine characterisation of the effects of these chromosomal regions on the major traits of interest is thus necessary to understand why these QTL are still segregating before using them in marker assisted selection programmes.

Only few QTL affecting litter size have so far been reported in the literature. Wilkie et al. [42], Cassady et al. [7] and Holl et al. [16] reported potential QTL affecting the number of stillborn piglets on SSC4, on SSC5 and SSC13, and on SSC12 and SSC14, respectively. With the exception of Noguera et al. [28], who obtained genome-wide significant QTL on SSC13 and SSC17, only QTL have been suggested for litter size at birth by Cassady et al. [7] on SSC11, King et al. [21] on SSC8, and de Koning et al. [10] on SCC7, SSC12, SSC14 and SSC17. Moreover, these QTL were obtained in crosses between selected lines [7] or in crosses involving the prolific Meishan breed (other studies). Except maybe for the SSC7 litter size QTL reported by de Koning et al. [10], the six chromosomal regions found in the present study for the numbers of born alive and stillborn piglets do not seem to match any of the previously published QTL.

Several candidate genes associated with litter size have been reported. Among them, the prolactin receptor (PRLR) gene locus [40] is close to the confidence interval bound of the QTL for LIVp detected on SSC16. On the contrary, no effect was found neither on SSC1 near the ESR (estrogen receptor) location nor in the area of RBP4 (retinol binding protein 4) gene on SSC14 for which Rothschild et al. [31,32] reported an effect on litter size.

Conversely, many loci affecting fatness and growth traits have been reported in the literature, some of which being close to the regions detected in the present study (see the review by Bidanel and Rothschild [4]). Among the 
most recent results, QTL for fatness have been reported by Lee et al. [24] and Kim et al. [20] on SSC2 and by Pierzchala et al. [29] on SSC17. Knott et al. [23], Beekman et al. [3] and Cepica et al. [8] also detected QTL for growth rate during the growing period on SSC4. All these studies were based on experimental crosses between divergent populations (Meishan $\times$ Large White, wild boar $\times$ Large White, Pietrain $\times$ Large White, Meishan $\times$ Pietrain, and wild boar $\times$ Meishan). It is possible that the QTL detected in the present study correspond to some of these reported loci. This conclusion is in agreement with the results of Evans et al. [13], van Wijk et al. [37] and Vidal et al. [39] who checked the segregation in commercial populations of several QTL detected using experimental crosses.

On the contrary, as already observed above for litter size, most loci affecting growth and fatness traits reported from studies based on intercrosses between distant breeds had no effect in the present study. This may result from the limited size of our design, the 8 male founders being homozygotes due to sampling, or the informative families being too small to reveal their effect significantly. Another likely explanation is that many of the QTL alleles that are found to be segregating between divergent breeds could have been fixed within commercial populations due to selection or random drift.

\subsection{Implications}

QTL mapping in commercial populations based on the use of existing familial structures is uncommon in the pig. The present study demonstrates the interest of such an approach, particularly for reproduction traits, which require long and expensive experimental designs. Several QTL were detected for fatness, growth and litter size. This tends to show that a part of the genetic variance in commercial populations can still be explained by the segregation of QTL with medium to large effects, despite a long period of intensive selection applied to these traits. These results, if confirmed, offer new opportunities regarding the use of marker assisted selection in pigs. The interest of implementing such tools has nevertheless to be evaluated using a cost/benefit approach and considering the breeding goals in LW and LR breeds.

Further work remains to be done on these experimental data, such as considering litter size performances of crossbred daughters to increase the power of the design. Some other traits will be investigated, such as litter size at weaning and reproduction intervals. From this preliminary detection, additional studies will be required to confirm the QTL reported and to map them more accurately. Additional paternal half-sib families will be searched in the national database 
in order to increase the power of the design. The use of multiple trait analysis and variance component methods (which allow relationships between families to be taken into account), as well as the joint use of linkage/association studies which are becoming possible with the availability of dense SNP marker maps, should be of great help for that purpose. Finally, the segregation of the identified haplotypes and the estimation of their effects in various commercial populations should also be investigated.

\section{ACKNOWLEDGEMENTS}

This project was funded in part by grants from the French Ministry of Agriculture (programme Actions Innovantes) and from Génopole, Toulouse, MidiPyrénées. The French collective breeding organisations are acknowledged for participating in the project, particularly for making the data and the DNA of animals available.

\section{REFERENCES}

[1] Andersson L., Haley C.S., Ellegren H., Knott S.A., Johansson M., Andersson K., Andersson-Eklund L., Edfors-Lilja I., Fredholm M., Hansson I., Hakansson J., Lundström K., Genetic mapping of quantitative trait loci for growth and fatness in pigs, Science 263 (1994) 1771-1774.

[2] Archibald A.L., Haley C.S., Brown J.F., Couperwhite S., McQueen H.A., Nicholson D., Coppieters W., Weghe A., Stratil A., Winterø A.K., Fredholm M., Larsen N.J., Nielsen V.H., Milan D., Woloszyn N., Robic A., Dalens M., Riquet J., Gellin J., Caritez J.C., Burgaud G., Ollivier L., Bidanel J.P., Vaiman M., Renard C., Geldermann H., Davoli R., Ruyter D., Verstege E.J.M., Groenen M.A.M., Davies W., Høyheim B., Keiserud A., Andersson L., Ellegren H., Johansson M., Marklund L., Miller J. R., Anderson Dear D.V., Signer E., Jeffreys A.J., Moran C., Tissier P., Muladno, Rothschild M.F., Tuggle C.K., Vaske D., Helm J., Liu H.C., Rahman A., Yu T.P., Larson R.G., Schmitz C.B., The PIGMaP consortium linkage map of the pig (Sus scrofa), Mamm. Genome 6 (1995) 157175.

[3] Beekmann P., Schröffel J., Moser G., Bartenschlager H., Reiner G., Geldermann H., Linkage and QTL mapping for Sus scrofa chromosome 1, J. Anim. Breed. Genet. 120 (2003) 1-10.

[4] Bidanel J.P., Rothschild M.F., Current status of quantitative trait locus mapping in pigs, Pig News Inf. 23 (2002) 39N-53N.

[5] Bidanel J.P., Milan D., Iannuccelli N., Amigues Y., Boscher M.Y., Bourgeois F., Caritez J.C., Gruand J., Le Roy P., Lagant H., Quintanilla R., Renard C., Gellin J., Ollivier L., Chevalet C., Detection of quantitative trait loci for growth and fatness in pigs, Genet. Sel. Evol. 33 (2001) 289-309. 
[6] Boichard D., Grohs C., Bourgeois F., Cerqueira F., Faugeras R., Neau A., Rupp R., Amigues Y., Boscher M.Y., Leveziel H., Detection of genes influencing economic traits in three French dairy cattle breeds, Genet. Sel. Evol. 35 (2003) 77101.

[7] Cassady J.P., Johnson R.K., Pomp D., Rohrer G.A., van Vleck L.D., Spiegel E.K., Gilson K.M., Identification of quantitative trait loci affecting reproduction in pigs, J. Anim. Sci. 79 (2001) 623-633.

[8] Cepica S., Stratil A., Kopecny M., Blazkova P., Schroffel Jr. J., Davoli R., Fontanesi L., Reiner G., Bartenschlager H., Moser G., Geldermann H., Linkage mapping and QTL-analysis for Sus scrofa chromosome 4, J. Anim. Breed. Genet. 120 (Suppl. 1) (2003) 28-37.

[9] Churchill G.A., Doerge R.W., Empirical threshold values for quantitative trait mapping, Genetics 138 (1994) 963-971.

[10] de Koning D.J., Rattink A.P., Harlizius B., Groenen M.A.M., Brascamp E.W., van Arendonk J.A.M., Detection and characterization of quantitative trait loci for growth and reproduction traits in pigs, Livest. Prod. Sci. 72 (2001) 185-198.

[11] de Koning D.J., Windsor D., Hocking P.M., Burt D.W., Law A., Haley C.S., Morris A., Vincent J., Griffin H., Quantitative trait locus detection in commercial broiler lines using candidate regions, J. Anim. Sci. 81 (2003) 1158-1165.

[12] Elsen J.M., Mangin B., Goffinet B., Boichard D., Le Roy P., Alternative models for QTL detection in livestock. I. General information, Genet. Sel. Evol. 31 (1999) 213-224.

[13] Evans G.J., Giffra E., Sanchez A., Kerje S., Davalos G., Vidal O., Illan S., Noguera J.L., Varona L., Velander I., Southwood O.I., de Koning D.J., Haley C.S., Plastow G.S., Andersson L., Identification of quantitative trait loci for production traits in commercial pig populations, Genetics 164 (2003) 621-627.

[14] Freyer G., Stricker C., Kühn C., Comparison of estimated breeding values and daughter yield deviations used in segregation and linkage analyses, Czech $\mathrm{J}$. Anim. Sci. 47 (2002) 247-252.

[15] Heyen D.W., Weller J.I., Ron M., Band M., Beever J.E., Feldmesser E., Da Y., Wiggans G.R., VanRaden P.M., Lewin H.A., A genome scan for QTL influencing milk production and health traits in dairy cattle, Physiol. Genomics 1 (1999) $165-175$.

[16] Holl J.W., Cassady J.P., Pomp D., Johnson R.K., A genome scan for quantitative trait loci and imprinted regions affecting reproduction in pigs, J. Anim. Sci. 82 (2004) 3421-3429.

[17] Hu Z.L., Dracheva S., Jang W., Maglott D., Bastiaansen J., Rothschild M.F., Reecy J.M., A QTL resource and comparison tool for pigs: PigQTLDB, Mamm. Genome 16 (2005) 792-800.

[18] Iannuccelli N., Woloszyn N., Arhainx J., Gellin J., Milan D., GEMMA: a database to manage and automate microsatellite genotyping, in: Proceedings of the 25th International Conference on Animal Genetics, 21-25 July 1996, Tours, France, p. 88.

[19] Jourdain C., Guéblez R., Le Hénaff G., Ajustement, à poids vif constant, des critères de contrôle en ferme chez le Large White et le Landrace Français, J. Rech. Porc. 21 (1989) 399-404. 
[20] Kim J.J., Rothschild M.F., Beever J., Rodriguez-Zas S., Dekkers J.C.M., Joint analysis of two breed cross populations in pigs to improve detection and characterization of quantitative trait loci, J. Anim. Sci. 83 (2005) 1229-1240.

[21] King A.H., Jiang Z., Gibson J.P., Haley C.S., Archibald A.L., Mapping quantitative trait loci affecting female reproductive traits on porcine chromosome 8 , Biol. Reprod. 68 (2003) 2172-2179.

[22] Knott S.A., Elsen J.M., Haley C.S., Methods for multiple-marker mapping of quantitative trait loci in half-sib populations, Theor. Appl. Genet. 93 (1996) 7180 .

[23] Knott S.A., Nystrom P.E., Andersson-Eklund L., Stern S., Marklund L., Andersson L., Haley C.S., Approaches to interval mapping of QTL in a multigeneration pedigree: the example of porcine chromosome 4, Anim. Genet. 33 (2002) 26-32.

[24] Lee S.S., Chen Y., Moran C., Cepica S., Reiner G., Bartenschlager H., Moser G., Geldermann H., Linkage and QTL mapping for Sus scrofa chromosome 2, J. Anim. Breed. Genet. 120 (2003) 11-19.

[25] Malek M., Dekkers J.C.M., Lee H.K., Baas T., Rothschild M.F., A molecular genome scan analysis to identify chromosomal regions influencing economic traits in the pig. I. Growth and body composition, Mamm. Genome 12 (2001) 630-636.

[26] Nagamine Y., Visscher P.M., Haley C.S., QTL detection and allelic effects for growth and fat traits in outbred pig populations, Genet. Sel. Evol. 36 (2004) 83-96.

[27] Neumaier A., Groeneveld E., Restricted maximum likelihood of covariances in sparse linear models, Genet. Sel. Evol. 30 (1998) 3-26.

[28] Noguera J.L., Rodriguez M.C., Varona L., Tomas A., Munoz G., Ramirez O., Barragan C., Arque M., Bidanel J.P., Amills M., Ovilo C., Sanchez A., Epistasis is a fundamental component of the genetic architecture of prolificacy in pigs, in: Proceedings of the 8th World Congress on Genetics Applied to Livestock Production, 13-18 August 2006, Belo Horizonte, Brazil, Communication 11-06.

[29] Pierzchala M., Cieslak D., Reiner G., Bartenschlager H., Moser G., Geldermann H., Linkage and QTL mapping for Sus scrofa chromosome 17, J. Anim. Breed. Genet. 120 (2003) 132-137.

[30] Rohrer G.A., Alexander L.J., Keele J.W., Smith T.P., Beattie C.W., A microsatellite linkage map of the porcine genome, Genetics 36 (1994) 231-245.

[31] Rothschild M.F., Jacobson C., Vaske D., Tuggle C., Wang L., Short T., Eckardt G., Sasaki S., Vincent A., McLaren D., Southwood O., van der Steen H., Mileham A., Plastow G., The estrogen receptor locus is associated with a major gene influencing litter size in pigs, Proc. Natl. Acad. Sci. USA 93 (1996) 201-205.

[32] Rothschild M.F., Messer L., Day A., Wales R., Short T., Southwood O., Plastow G., Investigation of the retinol-binding protein 4 (RBP4) gene as a candidate gene for increased litter size in pigs, Mamm. Genome 11 (2000) 75-77.

[33] Schulman N.F., Viitala S.M., de Koning D.J., Virta J., Mäki-Tanila A., Vilkki J.H., Quantitative trait loci for health traits in Finnish Ayrshire cattle, J. Dairy Sci. 87 (2004) 443-449. 
[34] Thomsen H., Reinsch N., Xu N., Looft C., Gruppe S., Kühn C., Brockmann G.A., Schwerin M., Leye-Horn B., Hiendleder S., Erhardt G., Medjugorac I., Russ I., Förster M., Brenig B., Reinhardt F., Reents R., Blümel J., Averdunk G., Kalm E., Comparison of estimated breeding values, daughter yield deviations and de-regressed proofs within a whole genome scan for QTL, J. Anim. Breed. Genet. 118 (2001) 357-370.

[35] Tribout T., Bidanel J.P., Ducos A., Garreau H., Continuous genetic evaluation of on farm and station tested pigs for production and reproduction traits in France, in: Proceedings of the 6th World Congress on Genetics Applied to Livestock Production, 11-16 January 1998, vol. 23, University of New England, Armidale, pp. 491-494.

[36] van der Beek S., van Arendonk J.A.M., Groen A.F., Power of two- and threegeneration QTL mapping experiments in an outbred population containing fullsib or half-sib families, Theor. Appl. Genet. 91 (1995) 1115-1124.

[37] van Wijk H.J., Dibbits B., Baron E.E., Brings A.D., Harlizius B., Groenen M.A.M., Knol E.F., Bovenhuis H., Identification of quantitative trait loci for carcass composition and pork quality traits in a commercial finishing cross, J. Anim. Sci. 84 (2006) 789-799.

[38] VanRaden P.M., Wiggans G.R., Derivation, calculation, and use of national animal model information, J. Dairy Sci. 76 (1991) 2737-2746.

[39] Vidal O., Noguera J.L., Amills M., Varona L., Gil M., Jiménez N., Davalos G., Folch J.M., Sanchez A., Identification of carcass and meat quality quantitative trait loci in a Landrace pig population selected for growth and leanness, J. Anim. Sci. 83 (2005) 293-300.

[40] Vincent A.L., Evans G., Short T.H., Southwood O.I., Plastow G.S., Tuggle C.K., Rothshild M.F., The prolactin receptor gene is associated with increased litter size in pigs, in: Proceedings of the 6th World Congress on Genetics Applied to Livestock Production, 11-16 January 1998, vol. 27, University of New England, Armidale, pp. 15-18.

[41] Weller J.I., Kashi Y., Soller M., Power of daughter and granddaughter designs for determining linkage between marker loci and quantitative trait loci in dairy cattle, J. Dairy Sci. 73 (1990) 2525-2537.

[42] Wilkie P.J., Paszek A.A., Beattie C.W., Alexander L.J., Wheeler M.B., Schook L.B., A genomic scan of porcine reproductive traits reveals possible quantitative trait loci (QTLs) for number of corpora lutea, Mamm. Genome 10 (1999) 573578.

\section{APPENDIX I (ONLINE): http://www.gse-journal.org}

\section{APPENDIX II}

The dependant variable $G M_{i j}$ for the $j^{\text {th }}$ parent from the $i^{\text {th }}$ male founder was computed by generalizing the "daughter yield deviation" approach described by VanRaden and Wiggans [38] to include the own performances of the parent. 


\section{DERIVATION OF $G_{i j}$ FOR REPRODUCTION TRAITS}

Consider the $j^{\text {th }}$ parent from the $i^{\text {th }}$ male of the design as animal $J$. $J$ has $K$ own records $\left(y_{J, 1}\right.$ to $\left.y_{J, K}\right)$ and $D$ daughters, and its $d^{\text {th }}$ daughter has $n_{d}$ records $\left(y_{d, 1}\right.$ to $\left.y_{d, n d}\right)$. The second parent of the $d^{\text {th }}$ daughter of $J$ is $m_{d}$.

The objective is to determine a pseudo performance $\left(G M_{J}\right)$ and its associated weight $\left(W_{J}\right)$ for the animal $J$ summarizing its actual own and daughters' phenotypes.

Let us assume that all the performances $y_{J, i}$ and $y_{d, i}$ have been previously adjusted for all non-genetic effects except permanent environmental effects, and let us consider the sample of population limited to animal $J$, its parents $p$ and $m$, its daughters $d(d$ in $[1 ; D])$, and its mates $m_{d}$.

With

$$
\lambda_{1}=\frac{\sigma_{e}^{2}}{\sigma_{a}^{2}}=\frac{\text { residual variance }}{\text { additive genetic variance }}
$$

and

$$
\lambda_{2}=\frac{\sigma_{e}^{2}}{\sigma_{\text {perm env }}^{2}}=\frac{\text { residual variance }}{\text { sow permanent environment variance }},
$$

the mixed model equations are:

$$
\left[\begin{array}{ll}
\mathbf{Z}^{\prime} \mathbf{Z}+\lambda_{1} \mathbf{A}^{-1} & \mathbf{Z}^{\prime} \mathbf{W} \\
\mathbf{W}^{\prime} \mathbf{Z} & \mathbf{W}^{\prime} \mathbf{W}+\lambda_{2} \mathbf{I}
\end{array}\right]\left[\begin{array}{l}
\boldsymbol{u} \\
\boldsymbol{p}
\end{array}\right]=\left[\begin{array}{l}
\mathbf{Z}^{\prime} \boldsymbol{y} \\
\mathbf{W}^{\prime} \boldsymbol{y}
\end{array}\right]
$$

where $\mathbf{Z}$ and $\mathbf{W}$ are, respectively, the incidence matrices for individual additive genetic values and permanent environmental effect, $\mathbf{A}$ is the numerator

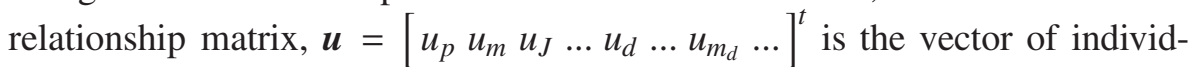
ual additive genetic values, and $\boldsymbol{p}=\left[p_{J} \ldots p_{d} \ldots\right]^{t}$ is the vector of permanent environmental effects for animal $J$ and its daughters.

The equations in (1) relative to the additive genetic values of animal $J$ and its $d^{\text {th }}$ daughter are, respectively:

$$
\begin{aligned}
-2 \lambda_{1} \frac{\left(u_{p}+u_{m}\right)}{2} & +\left[K+\lambda_{1}\left(2+\sum_{d=1}^{D} \frac{q_{d}}{4}\right)\right] u_{J} \\
- & \lambda_{1} \sum_{d=1}^{D}\left(\frac{q_{d}}{2} u_{d}\right)+\lambda_{1} \sum_{d=1}^{D}\left(\frac{q_{d}}{4} u_{m_{d}}\right)+K p_{J}=\sum_{k=1}^{K} y_{J, k}
\end{aligned}
$$


and

$$
-\lambda_{1} \frac{q_{d}}{2} u_{J}+\left(n_{d}+\lambda_{1} q_{d}\right) u_{d}-\left(\lambda_{1} \frac{q_{d}}{2}\right) u_{m_{d}}=\sum_{i=1}^{n_{d}} y_{d, i}-n_{d} p_{d}
$$

where $q_{d}$ equals 2 or $4 / 3$ whether the second parent of the $d^{\text {th }}$ daughter of parent $J$ is known or unknown.

The equations in (1) relative to the permanent environmental effects of animal $J$ and its $d^{\text {th }}$ daughter are, respectively:

$$
K u_{J}+\left(K+\lambda_{2}\right) p_{J}=\sum_{k=1}^{K} y_{J, k} \Leftrightarrow p_{J}=\frac{\sum_{k=1}^{K} y_{J, k}-K u_{J}}{K+\lambda_{2}}
$$

and

$$
n_{d} u_{d}+\left(n_{d}+\lambda_{2}\right) p_{d}=\sum_{i=1}^{n_{d}} y_{d, i} \Leftrightarrow p_{d}=\frac{\sum_{i=1}^{n_{d}} y_{d, i}-n_{d} u_{d}}{n_{d}+\lambda_{2}} .
$$

Replacing $p_{d}$ in (3) gives a new expression of $u_{d}$. After replacing $p_{J}$ and $u_{d}$ in (2) and rearranging, we obtain:

$$
\begin{aligned}
-2 \lambda_{1}\left(\frac{u_{p}+u_{m}}{2}\right)+ & {\left[2 \lambda_{1}+\frac{K \lambda_{2}}{K+\lambda_{2}}+\frac{\lambda_{1} \lambda_{2}}{4} \sum_{d=1}^{D} \frac{q_{d} n_{d}}{\lambda_{2} n_{d}+\lambda_{1} \lambda_{2} q_{d}+\lambda_{1} n_{d} q_{d}}\right] u_{J}=} \\
& \frac{\lambda_{2}}{K+\lambda_{2}} \sum_{k=1}^{K} y_{J, k}+\frac{\lambda_{1} \lambda_{2}}{2} \sum_{d=1}^{D} \frac{q_{d} \sum_{i=1}^{n_{d}}\left(y_{d, i}-\frac{u_{m_{d}}}{2}\right)}{\lambda_{2} n_{d}+\lambda_{1} \lambda_{2} q_{d}+\lambda_{1} n_{d} q_{d}}
\end{aligned}
$$

Setting

$$
W_{J}=\frac{K \lambda_{2}}{K+\lambda_{2}}+\frac{\lambda_{1} \lambda_{2}}{4} \sum_{d=1}^{D} \frac{q_{d} n_{d}}{\lambda_{2} n_{d}+\lambda_{1} \lambda_{2} q_{d}+\lambda_{1} n_{d} q_{d}}
$$

and

$$
G M_{J}=\left[\frac{\lambda_{2}}{K+\lambda_{2}} \sum_{k=1}^{K} y_{J, k}+\frac{\lambda_{1} \lambda_{2}}{2} \sum_{d=1}^{D} \frac{q_{d} \sum_{i=1}^{n_{d}}\left(y_{d, i}-\frac{u_{m_{d}}}{2}\right)}{\lambda_{2} n_{d}+\lambda_{1} \lambda_{2} q_{d}+\lambda_{1} n_{d} q_{d}}\right] \mid W_{J}
$$

the equation (6) becomes:

$$
-2 \lambda_{1}\left(\frac{u_{p}+u_{m}}{2}\right)+\left[2 \lambda_{1}+W_{J}\right] u_{J}=W_{J} G M_{J},
$$


which corresponds to the equation relative to the additive genetic value of animal $J$ in the MME $\left[\mathbf{Z}^{\prime} \mathbf{Z}+\mathbf{A}^{-\mathbf{1}} \lambda_{1}\right][\boldsymbol{u}]=\left[\mathbf{Z}^{\prime} \boldsymbol{y}\right]$ if animal $J$ only has one single own phenotype $G M_{J}$ with weight $W_{J}$ and no recorded daughter.

In the case where the animal $J$ has no own record, the expressions for $W_{J}(7 \mathrm{a})$ and $G M_{J}(7 \mathrm{~b})$ become:

$$
W_{J}=\frac{\lambda_{1} \lambda_{2}}{4} \sum_{d=1}^{D} \frac{q_{d} n_{d}}{\lambda_{2} n_{d}+\lambda_{1} \lambda_{2} q_{d}+\lambda_{1} n_{d} q_{d}}
$$

and

$$
G M_{J}=\left[\frac{\lambda_{1} \lambda_{2}}{2} \sum_{d=1}^{D} \frac{q_{d} \sum_{i=1}^{n_{d}}\left(y_{d, i}-\frac{u_{m_{d}}}{2}\right)}{\lambda_{2} n_{d}+\lambda_{1} \lambda_{2} q_{d}+\lambda_{1} n_{d} q_{d}}\right] / W_{J}
$$

\section{DERIVATION OF $G_{i j}$ FOR PRODUCTION TRAITS}

In this case, animals of generations 2 and 3 of the design have at most one own record, and the mixed model equations simplify to $\left[\mathbf{Z}^{\prime} \mathbf{Z}+\mathbf{A}^{-\mathbf{1}} \lambda_{1}\right][\boldsymbol{u}]=$ $\left[\mathbf{Z}^{\prime} \boldsymbol{y}\right]$. In the same way as above, we now get:

$$
W_{J}=1+\frac{\lambda_{1}}{4} \sum_{d=1}^{D}\left(\frac{q_{d}}{1+q_{d} \lambda_{1}}\right) \text { and } G M_{J}=\frac{y_{J}+\frac{\lambda_{1}}{2} \sum_{d=1}^{D}\left[\frac{q_{d}\left(y_{d}-u_{m_{d}} / 2\right)}{1+\left(\lambda_{1} q_{d}\right)}\right]}{W_{J}} .
$$

If the parent $J$ has no own phenotype, the previous formulas become:

$$
W_{J}=\frac{\lambda_{1}}{4} \sum_{d=1}^{D}\left(\frac{q_{d}}{1+q_{d} \lambda_{1}}\right) \text { and } G M_{J}=\frac{\frac{\lambda_{1}}{2} \sum_{d=1}^{D}\left[\frac{q_{d}\left(y_{d}-u_{m_{d}} / 2\right)}{1+\left(\lambda_{1} q_{d}\right)}\right]}{W_{J}} .
$$

\section{RELIABILITY OF PROOF OF ANIMAL $J$ BASED ON OWN AND PROGENY RECORDS}

The reliability $C D_{J}$ of the estimated breeding value of animal $J$ is given by $C D_{J}=1-\frac{P E V_{u_{J}}}{\sigma_{a}^{2}}$, where $P E V_{u_{J}}$ is the prediction error variance of the estimated breeding value of $J$. The available information for $J$ being limited to own and progeny records summarized in $G M_{J}$ with associated weight $W_{J}$, $P E V_{u_{J}}=\left[\mathbf{Z}^{\prime} \mathbf{Z}+\mathbf{A}^{-1} \lambda_{1}\right]^{-1} \sigma_{e}^{2}=\sigma_{e}^{2} /\left(\lambda_{1}+W_{J}\right)$, and $C D_{J}=W_{J} /\left(\lambda_{1}+W_{J}\right)$. 